\title{
ВЛИЯНИЕ ТЕКСТУРИРОВАННЫХ ПРОДУКТОВ ИЗ ЭКСТРУДИРОВАННОГО ЗЕРНА ОВСА НА КАЧЕСТВО ЗАТЯЖНОГО ПЕЧЕНЬЯ
}

\author{
M.A. Yanova, N.V. Prisukhina
}

\section{THE INFLUENCE OF TEXTURED OAT PRODUCTS ON THE QUALITY OF LINGERING COOKIES}

Янова Марина Анатольевна - канд. с.-х. наук, доц. каф. товароведения и управления качеством продукции АПК Красноярского государственного аграрного университета, г. Красноярск.

E-mail: yanova.m@mail.ru

Присухина Наталья Викторовна - канд. техн. наук, доц. каф. технологий хлебопекарного, кондитерского и макаронного производств Красноярского государственного аграрного университета, г. Красноярск. E-mail: nat3701@mail.ru

Цель исследования - изучение влияния текстурированных продуктов из экструдированного зерна овса на качество затяжного печенья. Задачи исследования: изучить влияние текстурированных продуктов из экструдированного зерна овса на замес теста для затяжного печенья и качество готового затяжного печенья. Методы исследования: ГОСТ 5898-87 «Изделия кондитерские. Методы оnределения кислотности и щелочности», ГОСТ 5900-73 «Изделия кондитерские. Методы определения влаги и сухих веществ», ГОСТ 10114-80 «Изделия кондитерские мучные. Метод определения намокаемости». Для составления смеси использовался текстурат из экструдированного зерна овса. Изучали овсяный текстурат трех фрракций: мелкой (размер частиц до 450 мкм), средней (размер частиц до 800 мкм) и крупной (размер частиц до 1000 мкм). И далее его смешивали с мукой пшеничной высшего сорта в количество от 5 до $25 \%$. В мучных смесях использованы мелкая, средняя и крупная фрракции овсяного текстурата в количества 25 \% и числом падения 322, 325 и
Yanova Marina Anatolyevna - Cand. Agr. Sci., Assoc. Prof., Chair of Merchandizing and Product Quality Control of Agrarian and Industrial Complex, Krasnoyarsk State Agrarian University, Krasnoyarsk. E-mail: yanova.m@mail.ru

Prisukhina Natalya Viktorovna - Cand. Techn. Sci., Assoc. Prof., Chair of Technologies of Baking, Confectionery and Macaroni Productions, Krasnoyarsk State Agrarian University, Krasnoyarsk.

E-mail: nat3701@mail.ru

326 соответственно. В результате исследования рецептур с заменой части муки пшеничной на овсяный текстурат наблюдалось сокращение продолжительности замеса теста с увеличением размера фракций (50 мин - контроль, 43 мин - образец из крупной фрракции). Анализ качества готовых изделий показал, что с увеличением размера частии незначительно снижается влажность готовых изделий, при этом повышается намокаемость. Показатели полученных образцов затяжного печенья соответствуют требованиям ГОСТ. Высокую дегустационную оценку получил образеи с внесением 25 \% текстурата из экструдированного зерна овса средней фрракции.

Ключевые слова: текстурат, экструдированное зерно овса, мучная смесь, затяжное печенье, число падения, водопоглотительная способность.

The research objective was studying the influence of textured products from extruded grain of oats on the quality of lingering cookies. The research problems were to study the influence of tex- 
tured products from extruded grain of oats on the batch of dough for lingering cookies and the quality of ready lingering cookies. The research methods: State Standard 5898-87 "Confectionery. The methods of determination of acidity and alkalinity", State Standard 5900-73 "Confectionery. The methods of definition of moisture and solids", State Standard 10114-80 "Flour confectionery. The method of wetness definition". For drawing up mix the texturate from extruded grain of oats was used. Oat texturate of three fractions: small (the size of particles was up to 450 microns), average (the size of particles was up to 800 microns) and large (the size of particles was up to 1000 microns) were studied. And further it was mixed with premium wheat flour in the quantity from 5 to $25 \%$. In flour mixes small, average and large fractions of oat texturate in number of $25 \%$ and number of falling 322, 325 and 326 respectively were used. As a result of the research of the recipes with the replacement of part of wheat flour by oat texturate reduction of duration of the batch of dough with increase in the size of fractions was observed (50 minutes - control, 43 minutes the sample from large fraction). The analysis of the quality of finished products showed that with increase in the size of particles the humidity of finished products slightly decreased, thus the wetness raised. The indicators of the received samples of lingering cookies conform to the requirements of State Standard. High tasting assessment was received by the sample with introduction of $25 \%$ of the texturate from extruded grain of oats of average fraction.

Keywords: texturate, extruded oat grain, flour mixture, lingering cookies, number of drops, water absorption capacity.

Введение. В последние годы все большее внимание уделяется здоровому образу жизни и соответственно здоровому питанию. Мучные кондитерские изделия, в частности печенье, пользуется огромным спросом у всех слоев населения. Поэтому обогащение таких изделий с использованием недорого сырья является актуальной задачей [1].
В основе создания новых пищевых продуктов лежит проблема создания качественной и безопасной продукции [2]. На качество и потребительскую активность готовых изделий оказывает влияние качество сырья, технологические режимы производства мучных кондитерских изделий, особенно замес теста [3].

Тесто для затяжного печенья содержит меньше сахара и жира в отличие от сахарного печенья, но больше влаги, за счет чего образуется тесто с упруго-эластичными свойствами. За счет этого на поверхность затяжного печенья не наносится рисунок, так как он не сохраняет свою форму при выпечке. Наносятся только проколы для выхода лишней влаги. Чтобы придать затяжному тесту пластические свойства для формования изделий, тесто подвергают многократной прокатке. Общее количество прокаток определяется свойствами муки.

На сегодняшний день требования к муке для кондитерской отрасли отсутствуют, при этом имеются нормативные документы для муки хлебопекарной [4].

Основная роль в образовании теста принадлежит белкам муки, способным набухать при необходимой влажности. Работа посвящена изучению влияния текстурированного продукта из экструдированного зерна овса на образование теста затяжного печенья и качество готового изделия.

В муке две основных части - это белковые вещества и крахмал. Они обладают различной водопоглотительной способностью. Водопоглотительная способность зависит от температурных режимов, структуры белка и состояния крахмальных зерен. При помоле муки часть крахмальных зерен повреждается, что приводит к повышению водопоглотительной способности до $200 \%$ [5].

При замесе теста для затяжного печенья наиболее полное набухание белков происходит при температуре $40{ }^{\circ} \mathrm{C}$, более низкие температуры снижают набухаемость. Отмечается частичное связывание крахмала водой, следовательно, рекомендуется использовать муку со слабой клейковиной, так как процесс набухания в ней протекает быстрее. 
Температура замеса затяжного теста находится в близких пределах для активной работы таких ферментов, как протеиназ и амилазы, а также некоторых окислительных ферментов, что приводит к ухудшению качества теста. Но продолжительный замес теста приводит к большему захвату кислорода и активации протеолитических ферментов, что улучшает свойства теста [5].

«Число падения» - это показатель, который характеризует активность таких фрерментов, как амилазы. При высокой активности амилазы повышается также активность протеолитических ферментов, что связано непосредственно с влагоудерживающей способностью муки и качеством теста [5].

То есть низкое число падения (ЧП) показывает высокое содержание амилаз, под действием которых происходит частичная денатурация белковых веществ и расщепление крахмала, вследствие чего наибольшая часть веществ переходит в жидкую фазу теста, что ухудшает его физические свойства.

Цель исследования: изучение влияния текстурированных продуктов из экструдированного зерна овса на качество затяжного печенья.

\section{Задачи исследования:}

1) изучить влияние текстурированных продуктов из экструдированного зерна овса на замес теста для затяжного печенья;

2) изучить влияние текстурированных продуктов из экструдированного зерна овса на качество готового затяжного печенья.

Методы исследования: ГОСТ 5898-87 «Изделия кондитерские. Методы определения кислотности и щелочности», ГОСТ 5900-73. «Изделия кондитерские. Методы определения влаги и сухих веществ», ГОСТ 10114-80 «Изделия кондитерские мучные. Метод определения намокаемости».

Результаты исследования. В результате обработки зерна с помощью экструзии злаковых культур наблюдаются химические и молекулярные изменения основных веществ. При обработке происходит денатурация белков. Гидролиз белка сопровождается изменением его жироудерживающей, водоудерживающей способности. Белки муки лучше диспергируют в воде, приобретается способность образовывать вязкие суспензии в холодной воде, образуется эффект холодного набухания [7].

После проведения обработки зерна экструзией зерно размололи в муку, разделили на 3 фрракции: мелкую (размер частиц до 450 мкм), среднюю (размер частиц до 800 мкм) и крупную (размер частиц до 1000 мкм).

Полученные экструдированные зерновые продукты смешивали с мукой пшеничной хлебопекарной в различных дозировках (5-25\%) и определяли число падения составленных смесей.

Наилучший результат по числу падения (ЧП) достигнут при составлении смеси пшеничной муки с текстуратом из овса крупной фракции в количестве $5 \%$ и равен 389 с. Но хоть верхний показатель ЧП не регламентируется, слишком высокие показатели указывают на сниженную активность собственных ферментов муки. Поэтому для разработки затяжного печенья выбрана мучная смесь мелкой, средней и крупной фракции и внесение текстурата из овса в количества $15 \%$ и числом падения 341, 352 и 355 соответственно. В качестве контроля выбрана рецептура печенья «Зоологическое».

Из ранее проведенных исследований известно, что чем крупнее фракция, тем выше водопоглотительная способность мучной смеси.

При замесе затяжного теста большая часть воды находится в свободном состоянии, что позволяет ей проникать в межмолекулярное пространство белков и набухать.

Для замеса упруго-эластичного теста затяжного печенья необходимо достаточное количество свободной воды. Чем выше водопоглотительная способность, тем быстрее протекает замес теста.

На рисунке представлена зависимость продолжительности замеса теста из составленных мучных смесей от размера фракции.

На рисунке 1 видно, что продолжительность замеса снижается с увеличением размера фракции и внесением текстурированного зерна овса. Это связано с тем, что чем меньше размер частиц муки, тем меньше их удельная поверхность и, соответственно, за один и тот же про- 
межуток времени такая мука будет связывать меньше воды. А также связано с повышающейся водопоглотительной способностью текстурированного зерна в отличие от контроля.
В готовом печенье определяли основные показатели качества согласно ГОСТ 24901-2014 [8]. Результаты оценки фризико-химических показателей представлены на рисунках 2-4.

\section{Продолжительность замеса при частоте 22 об/мин, мин}

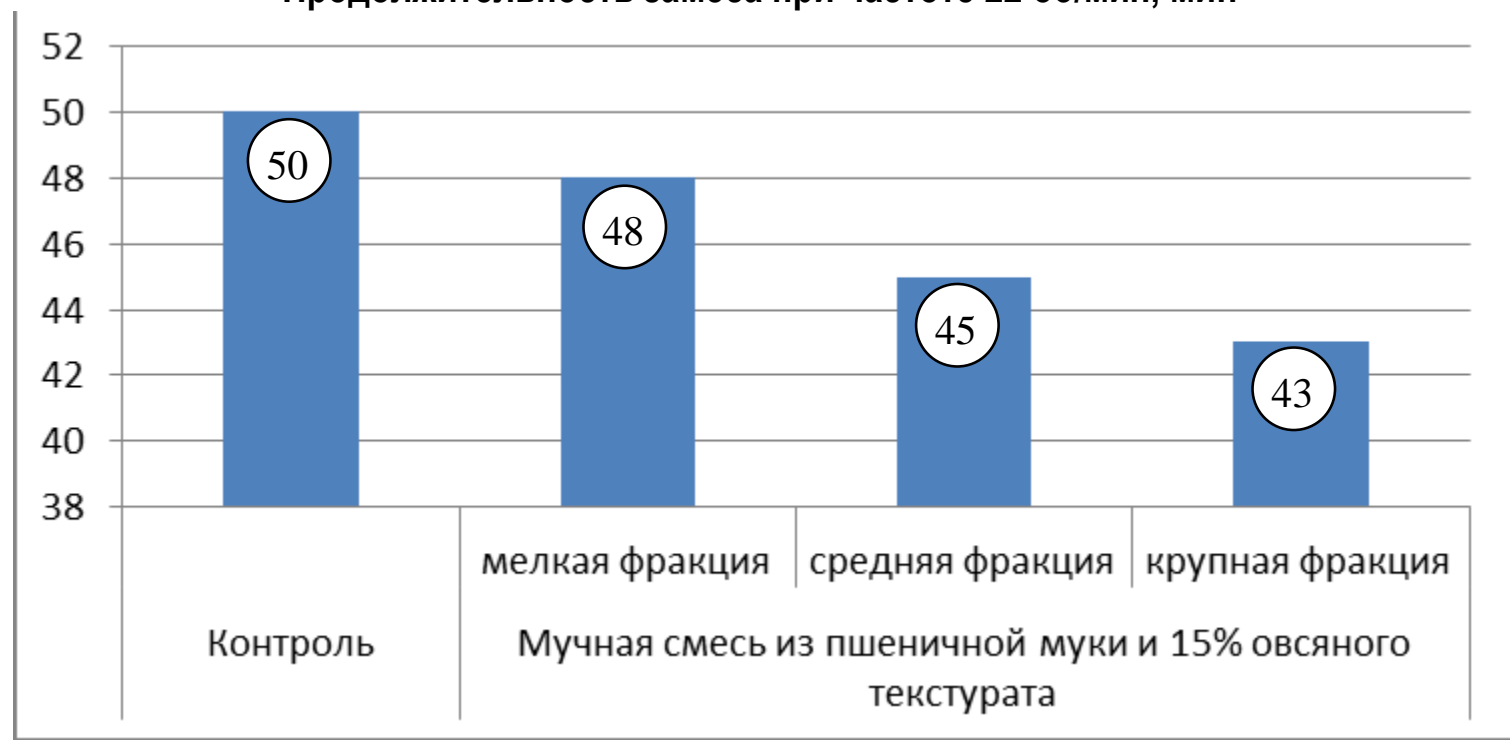

Puc. 1. Зависимость влияния продолжительности замеса теста от размера фракции текстурата из экструдированного зерна овса

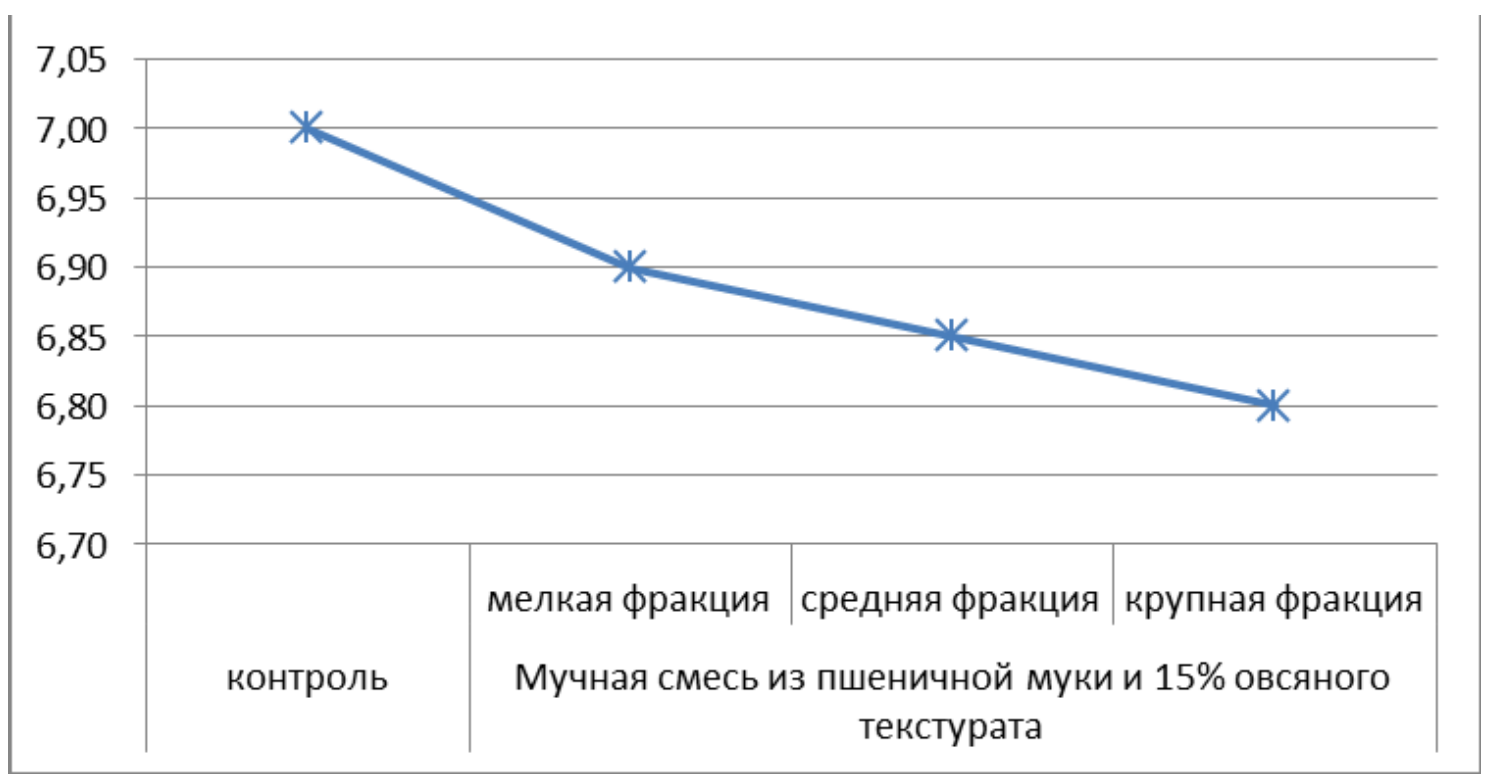

Puc. 2. Массовая доля влаги в печенье в зависимости от фрракции текстурата из экструдированного зерна овса, \%

На рисунке 2 видно, что влажность печенья из мучных смесей незначительно снижается, связано это с увеличением водопоглотительной способности. По ГОСТу массовая доля влаги должна быть не более $9 \%$. 


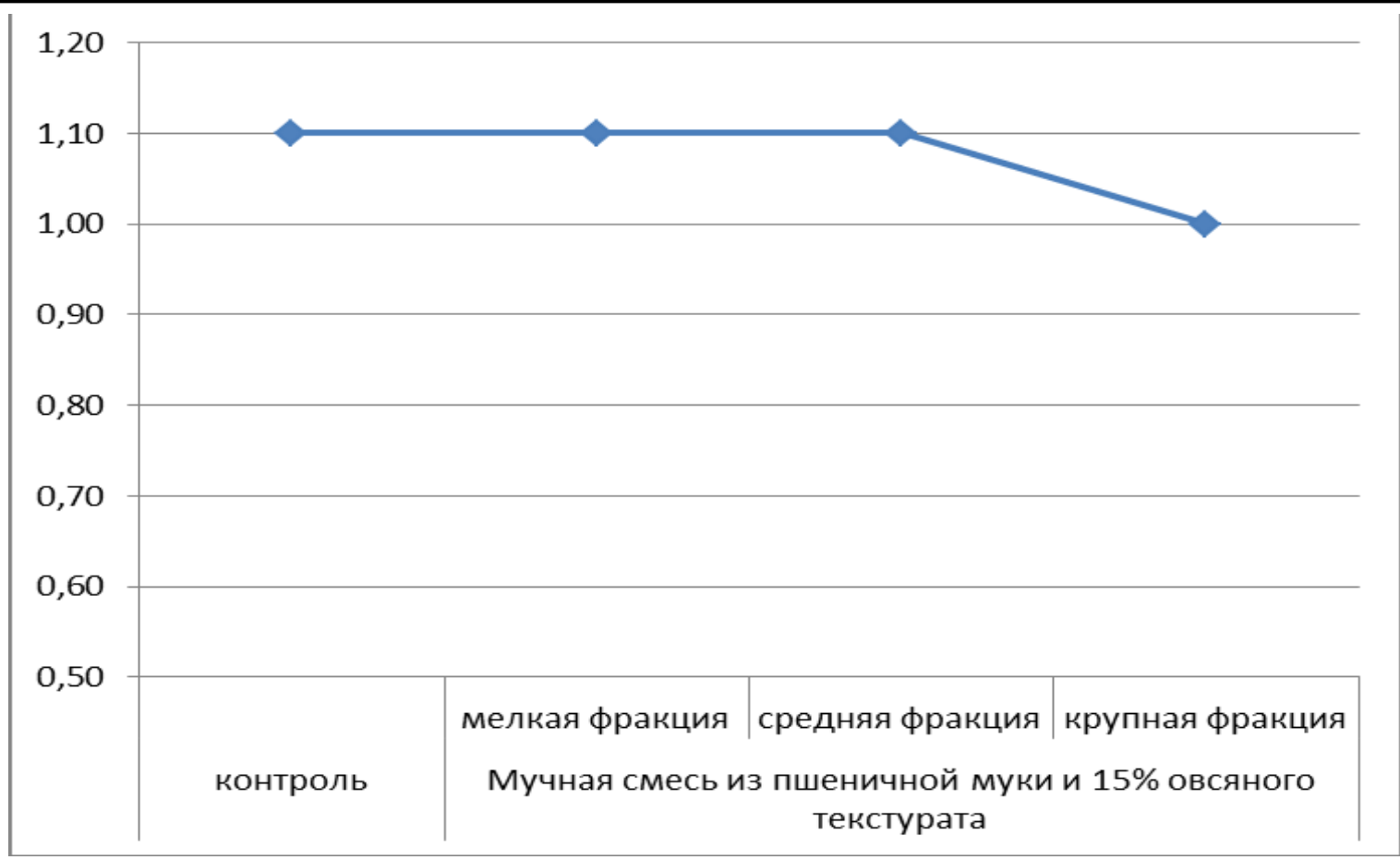

Puс. 3. Щелочность печенья в зависимости от фрракции текстурата из экструдированного зерна овса, град.

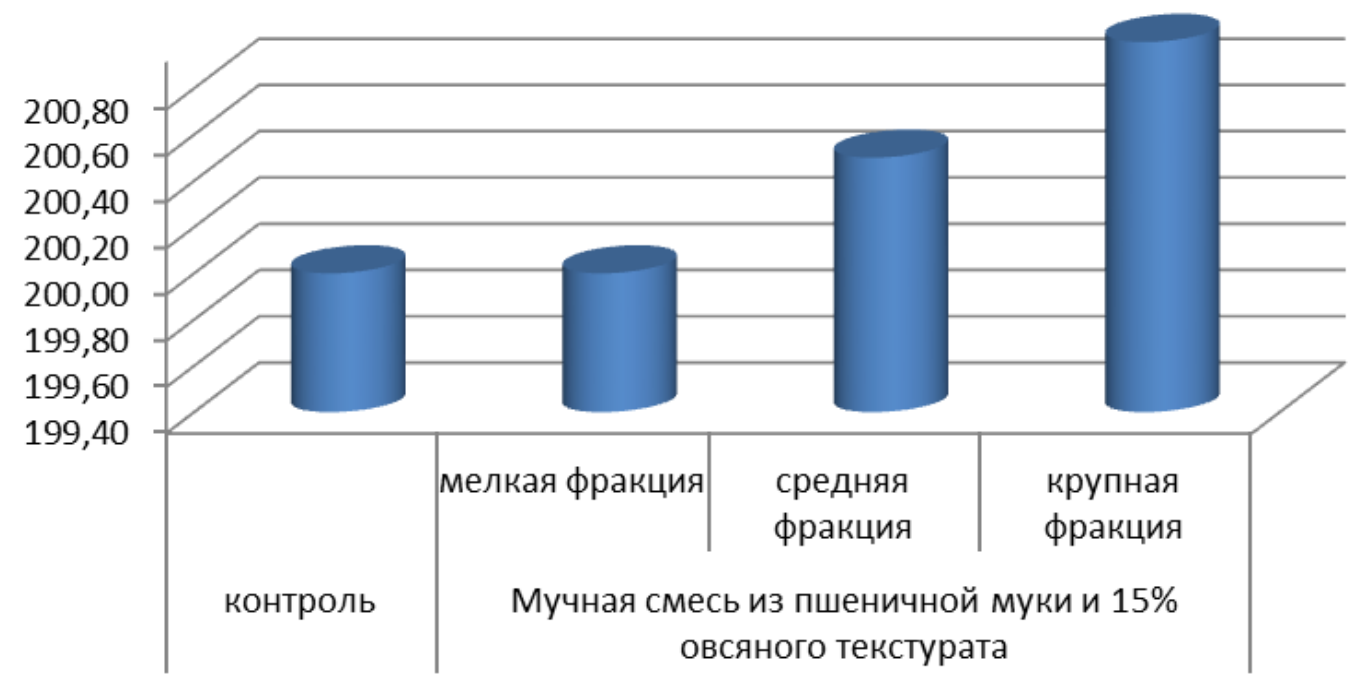

Puc. 4. Намокаемость печенья в зависимости от фрракции текстурата из экструдированного зерна овса, \%

На рисунке 4 видно, что в печенье из мучной смеси с текстурированным зерном овса намокаемость незначительно увеличивается, связано это с тем, что на поверхности появляются микротрещины, примерно как на овсяном печенье, что способствует более быстрому проникновению воды внутрь и намоканию.
В зависимости от размера фракции, как уже обозначалось ранее, водопоглотительная способность меняется.

Дегустационная оценка готового затяжного печенья с текстуратами приведена на рисунке 5. 


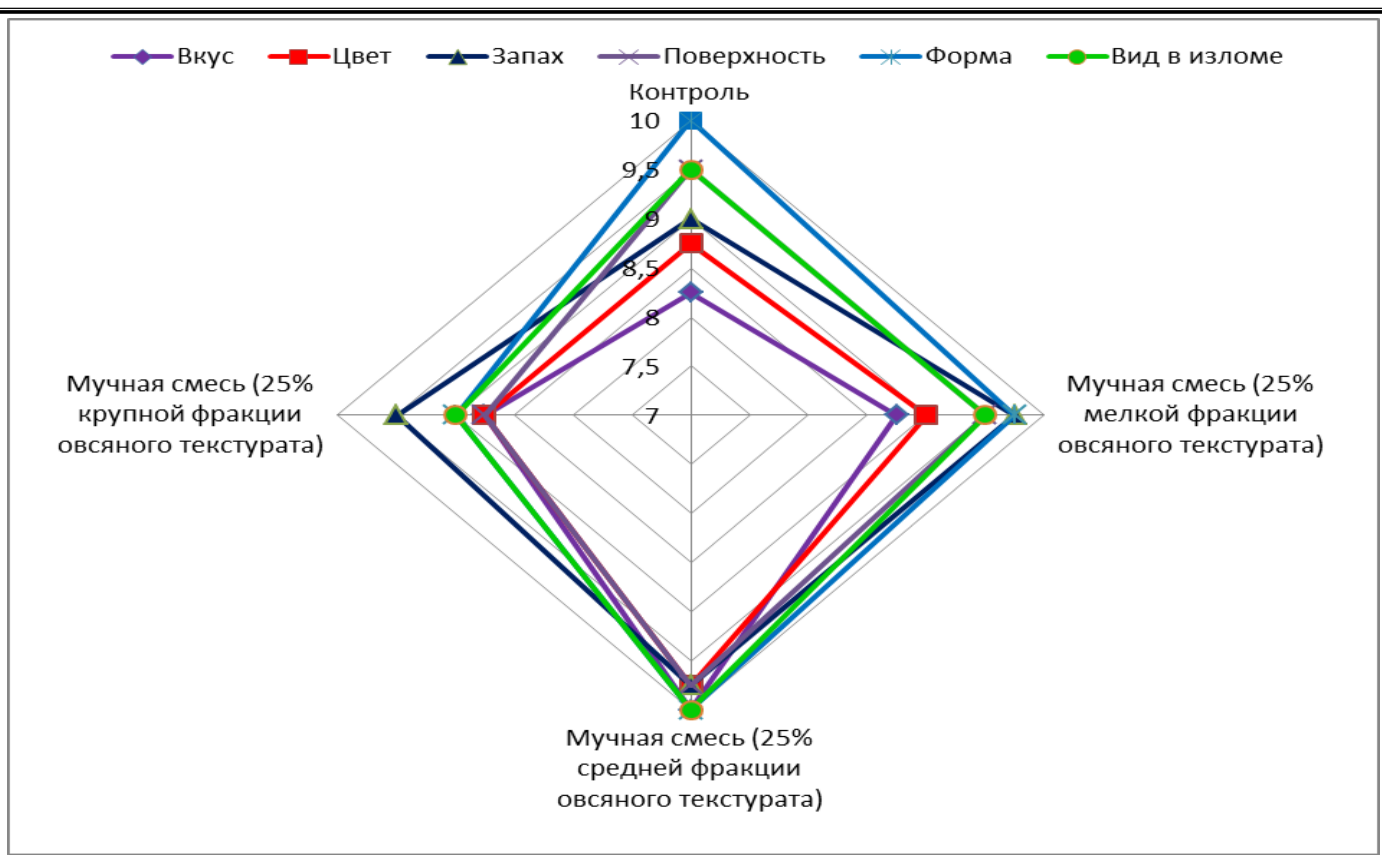

Puс. 5. Дегустационная оценка печенья с текстуратом из экструдированного зерна овса

Дегустационную оценку проводили по 10балльной шкале. В дегустации принимали участие 4 дегустатора. После оценки каждого были просчитаны средние значения по каждому образцу и построена диаграмма, на которой видно, что наивысшую оценку получил образец печенья на основе мучной смеси из пшеничной муки и $15 \%$ содержанием овсяного текстурата средней фракции.

Выводы. В результате проведенных исследований можно сделать вывод о том, что применение мучных смесей на основе текстурированного зерна овса оказывает благоприятное воздействие на органолептическую оценку затяжного печенья. Физико-химические показатели соответствуют ГОСТ 24901-2014. Продолжительность замеса теста для печенья сокращается за счет введения в рецептуру текстурированных продуктов из экструдированного зерна овса, обладающих повышенной влагоудерживающей способностью, это позволит повысить производительность предприятия.

\section{Литература}

1. Матвеева Н.С., Ивкова А.И. Совершенствование рецептуры и технологии сахарного печенья на основе растительного масла «Пальмеон» // Вестн. Омского ГАУ. 2018. - № 4 (32). - C. 57-66.
2. Кочетов В.К., Гончар В.В., Росляков Ю.Ф., Вершинина О.Л. Обеспечения качества и безопасности производствановых сортов мучных кондитерских изделий на основе принципов ХАССП // Торты. Вафоли. Печенье. Пряники-2018. Производство - Рынок Потребитель: мат-лы докл. бизнес-конф. I Междунар. пром. Академия. - М., 2018. C. 67-71.

3. Корячкина С.Я., Лазарева Т.Н., Густинович В.Г., Жаркова И.М. Разработка рецептуры и технологии затяжного печенья повышенной антиоксидантной активности // Хлебопродукты. - 2018. - № 7. - С. 57-59.

4. Мелешкина Е.П., Ческидова А.С.,Коваль А.И., Кириллова Е.В. Пшеничная мука как сырьё для кондитерскогопроизводства: разработка метода оценки качества вафель и исследование влияния реологических свойств теста по альвеографуу на качество вафрель // Торты. Вафлли. Печенье. Пряники2018. Производство - Рынок - Потребитель: мат-лы докл. бизнес-конф. / Междунар. пром. Академия. - М., 2018. - С. 59-64.

5. Зубченко А.В. Физико-химические основы технологии кондитерских изделий / Воронеж. гос. технол. академия. - Воронеж, 1997. - 147 c.

6. Янова М.А., Присухина Н.В., Горбунова Т.А. Влияние текстурированных продуктов из 
зернового сырья на состояние углеводноамилазного комплекса в мучных смесях для хлебобулочных изделий // Вестник КрасГАУ. - 2019. - № 11. - С. 127-132.

7. Янова М.А., Росляков Ю.Ф. Разработка рецептур затяжного печенья с использованием муки, полученной из экструдированного зерна пшеницы // Торты. Вафрли. Печенье. Пряники-2018. Производство - Рынок Потребитель: мат-лы докл. бизнес-конф. I Междунар. пром. академия. - М., 2018. C. $127-131$.

8. ГОСТ 24901-2014. Печенье. Общие технические условия. - М., 2014.

\section{Literatura}

1. Matveeva N.S., Ivkova A.I. Sovershenstvovanie receptury i tekhnologii saharnogo pechen'ya na osnove rastitel'nogo masla «Pal'meon» // Vestn. Omskogo GAU. 2018. - № 4 (32). - S. 57-66.

2. Kochetov V.K., Gonchar V.V., Roslyakov Yu.F., Vershinina O.L. Obespecheniya kachestva i bezopasnosti proizvodstvanovyh sortov muchnyh konditerskih izdelij na osnove principov HASSP // S. 67-71.

3. Koryachkina S.Ya., Lazareva T.N., Gustinovich V.G., ZHarkova I.M. Razrabotka receptury i tekhnologii zatyazhnogo pechen'ya povyshennoj antioksidantnoj aktivnosti // Hleboprodukty. - 2018. - № 7. - S. 57-59.
4. Meleshkina E.P., CHeskidova A.S., Koval' A.I., Kirillova E.V. Pshenichnaya muka kak syr'yo dlya konditerskogoproizvodstva: razrabotka metoda ocenki kachestva vafel' i issledovanie vliyaniya reologicheskih svojstv testa po al'veografu na kachestvo vafel' // Torty. Vafli. Pechen'e. Pryaniki-2018. Proizvodstvo Rynok - Potrebitel': mat-ly dokl. biznes-konf. I Mezhdunar. prom. Akademiya. - M., 2018. S. 59-64.

5. Zubchenko A.V. Fiziko-himicheskie osnovy tekhnologii konditerskih izdelij / Voronezh. gos. tekhnol. akademiya. - Voronezh, 1997. $147 \mathrm{~s}$.

6. Yanova M.A., Prisuhina N.V., Gorbunova T.A. Vliyanie teksturirovannyh produktov iz zernovogo syr'ya na sostoyanie uglevodnoamilaznogo kompleksa $v$ muchnyh smesyah dlya hlebobulochnyh izdelij // Vestnik KrasGAU. - 2019. - № 11. - S. 127-132.

7. Yanova M.A., Roslyakov Yu.F. Razrabotka receptur zatyazhnogo pechen'ya $\mathrm{s}$ ispol'zovaniem muki, poluchennoj iz ekstrudirovannogo zerna pshenicy // Torty. Vafli. Pechen'e. Pryaniki-2018. Proizvodstvo Rynok - Potrebitel': mat-ly dokl. biznes-konf. I Mezhdunar. prom. akademiya. - M., 2018. S. 127-131.

8. GOST 24901-2014. Pechen'e. Obshchie tekhnicheskie usloviya. - M., 2014. 